\title{
Benchmarking Analysis of Carbon Emission in China and Foreign Countries from the Perspective of Urbanization
}

\author{
Jun Wang $^{1,{ }^{*}}$ and Hua Zhao ${ }^{2}$ \\ ${ }^{1}$ No.130, MeiLong Rd, East China University of Science and Technology, Shanghai, China \\ ${ }^{2}$ No.130, MeiLong Rd, East China University of Science and Technology, Shanghai, China
}

\begin{abstract}
With the further aggravation of global warming and the increasingly serious problems of ecological environment, the construction of low-carbon cities has become an inevitable choice for the global response to climate change and the sustainable development of economy and society. In order to understand the basic situation of China's low-carbon cities more specifically, this paper selects countries with different urbanization rates to carry out benchmarking analysis with China, hoping to draw on the experience of other countries from the national level through multi-dimensional comparison, and guide the direction of China's future urban development. Firstly, this paper selects the basic indicators such as the total amount of carbon dioxide emissions, per capita carbon emissions and carbon emissions per unit GDP of each country; Secondly, it compares the proportion of coal in energy and other indicators, and analyzes the energy structure of each country in depth; Thirdly, it compares the trend of carbon emissions in each country among 1990-2017. Finally, in order to reflect the carbon emission in the development of urbanization, this paper uses the "urbanization carbon emission index", which is the ratio of per capita carbon emission and urbanization rate, to show the relationship between the degree of urbanization and carbon emission. Through benchmarking analysis, we can more clearly understand the overall trend of low-carbon city construction in different countries, recognize the gap between China and other countries, and better guide the development of low-carbon cities in China in the future.
\end{abstract}

\section{Introduction}

In the 21 st century, the severe situation of global climate change and energy depletion has seriously threatened human survival. The United Nations Intergovernmental Panel on climate change (IPCC) released the IPCC special report on global warming of $1.5^{\circ} \mathrm{C}$ on October 8 , 2018. The report points out that compared with the pre industrial level, the global temperature rise has reached $1{ }^{\circ} \mathrm{C}$, which has resulted in the increase of extreme weather events, the decrease of Arctic sea ice and the rise of sea level[1]. In order to achieve the temperature control target of $1.5{ }^{\circ} \mathrm{C}$, it is necessary for countries all over the world to carry out far-reaching and forwardlooking transformation in energy, land, urban and industrial systems.

Nowadays, the construction of low-carbon cities has almost become the common goal of all countries. Many countries have introduced relevant laws and regulations to promote the development of low-carbon cities. For China, it is still in the stage of accelerated urbanization. Facing the threat of climate change, low-carbon cities are obviously the inevitable choice for China to achieve sustainable development.

In order to compare the construction level of Chinese and foreign low-carbon cities and understand the development of Chinese low-carbon cities more comprehensively, this paper selects countries with different urbanization rates to carry out benchmarking analysis with China. By comparing the main low-carbon construction indicators, we can more intuitively find out the differences between China and other countries in lowcarbon city construction, recognize the shortcomings of its own development, and learn from the experience of other countries at the national level.

\section{Trends of low carbon construction in China and abroad}

\subsection{International emission reduction trends}

In the face of increasingly serious climate problems, various countries and international organizations have to take active actions to deal with climate change. From December 2 to 15,2018 , the 24th conference of the parties to the United Nations Framework Convention on climate change (cop24) opened in Katowice, Poland, which is the most important climate negotiation since 2015 [2]. The parties basically reached consensus on the mechanisms and rules of the $<$ Paris Agreement $>$, such as independent contribution, mitigation and adaptation, climate finance, technology, capacity-building, global inventory and transparency, and reached the

* Corresponding author: denief@163.com 
implementation rules of the <Paris Agreement $>$, which changed the vision into reality. The main purpose of this conference is to strengthen the enthusiasm of all parties to promote climate action and support, show the trend of global low-carbon transformation, improve the confidence of the international community to cooperate in response to climate change, and strengthen the political will of all parties to promote global climate governance.

In November 2018, the European Commission published the long-term development strategy of low greenhouse gas emissions of "A Clean Planet for All", aiming to achieve "carbon neutrality" by 2050 . That is, to reduce net carbon emissions to zero [3]. This is the first major economy in the world to put forward the goal of "carbon neutrality" by the middle of the 21 st century.

The UK's policy progress is mainly reflected in $<$ The Second National Adaptation Programme 2018-2023> released by the Ministry of Environment, Food and Rural Affairs in July 2018. Aiming at the priority areas of climate change in the UK, the plan determines the actions that the UK government and other departments need to take in the next five years to meet the challenges of adaptation to climate change [4].

The Canadian government has formulated a plan to protect the environment and achieve economic growth at the same time. The plan also has a positive environmental and social effect in Canada, which makes the carbon emissions decrease and the economy grow [5]. At the same time, the Canadian government has worked with provinces and regions for two years to give local governments enough flexibility to design their own climate plans and to price the carbon based pollution.

The Nordic countries Finland, Sweden, Norway, Denmark and Iceland signed a joint statement on climate change in January 2019, saying that they will reasonably increase their efforts to cope with climate change and strive to achieve the goal of "carbon neutrality" faster than other countries in the world [6].

Germany is the largest coal user in Europe. On January 26, 2019, the German Coal Commission announced for the first time a schedule for phasing out coal-fired power generation, claiming that Germany will close all coal-fired power plants by 2038 . At the same time, the government will give enterprises and consumers in the affected areas 2 billion euros a year, a total of 40 billion euros in compensation[7]. This campaign of coal elimination will be the beginning of accelerating the transformation of German energy market.

\subsection{Current situation of low carbon city construction in China}

China started late in the construction of low-carbon cities, and there is a significant gap between China and countries with high economic development level. However, as a "responsible big country", China has been actively responding to climate change. At the 19th National Congress of the Communist Party of China, climate change was listed as an important non-traditional security threat in the world and a common challenge faced by human beings. It was proposed that "we should adhere to environmental friendliness, cooperate with climate change, and protect the homeland on which human beings depend for survival". At the same time, the paper puts forward the path of low-carbon economic development, which is suitable for the global emission reduction target, and provides Chinese wisdom and experience for the global ecological civilization and sustainable development.

In recent years, no matter at the national or local level, China has put forward many new policies to guide the construction of low-carbon cities. The "four ones" proposed in the National Congress in 2019 emphasized the importance of ecological civilization construction [8] $<$ The three year action plan for winning the blue sky defense war $>$ issued by the State Council determines the overall idea, basic objectives, main tasks and safeguard measures for air pollution prevention and control, puts forward the practice table and road map for winning the blue sky defense war, and defines the quantitative carbon reduction index and completion time limit [9]

At the local level, it mainly advocates sharing regional development. In March 2019, the work report of the government clearly stated that "the development of regional integration in the Yangtze River Delta should be promoted to a national strategy, the outline of development plan should be formulated and implemented, the development of the Yangtze River Economic Belt should adhere to the coordination of the upstream, the middle and the downstream, strengthen the ecological protection and restoration, the construction of comprehensive transportation system, and build a highquality economic belt for development", which indicates that the development of regional integration in the Yangtze River Delta has entered a major breakthrough Breaking stage [10]. In January 2019, the State Council approved the master plan of Xiong'an New District of Hebei Province (2018-2035), and established the shortterm and medium-term and long-term construction objectives of Xiong'an New District [11]. As the most remarkable new area, the completion of Xiong'an new area will lead the national regional development and become a new engine of low-carbon economic system in the new era.

For the waste classification industry, 2019 is also their "legislative year". As of May 2019, 46 key cities have carried out "schedule planning" for waste classification in the form of opinions, implementation plans or action plans. In addition to legislation, many cities have also carried out model innovation in waste classification. Ningbo adopts the mode of economic stimulus waste classification, especially in the revision of the charging standards for domestic waste and kitchen waste in non residential units, and proposes different types of waste differential charges to encourage citizens to separate the kitchen waste and promote the construction of lowcarbon cities.

\section{Benchmarking analysis of carbon emission in China and abroad}




\subsection{Establishment of analytical model}

In order to realize the basic situation of China's lowcarbon development in a more comprehensive way, this paper selects countries with different urbanization rates for benchmarking analysis, hoping to draw lessons from the national level through multi-dimensional comparison, and guide the direction of China's low-carbon city development.

In terms of the choice of comparative countries, according to Northam's theory, urbanization can be divided into three stages: primary stage, accelerated stage and stable stage [12], that is, the urbanization rate can be divided into three levels: below $30 \%, 30 \%-70 \%$, and over $70 \%$. Countries with different urbanization stages are selected for comparison with China to explore the construction of low-carbon cities with different urbanization rates. In terms of the choice of comparative countries in stable stage, this paper selects eight representative member countries (the United States, the United Kingdom, Germany, Sweden, Australia, Japan, South Korea, Mexico) from OECD(The Organization for Economic Co-operation and Development). As for the accelerated stage, this paper selects South Africa and Indonesia as the two cases, and India as the comparative country in the primary stage.

As for the selection of low-carbon construction indicators, this paper mainly chooses the carbon emission related indicators based on energy consumption. Through the benchmarking analysis of the basic situation of carbon emission, energy structure and carbon emission change trend, we can further explore the differences between the construction of low-carbon cities at home and abroad. Finally, in order to reflect the carbon emission in the development of urbanization, this paper uses the "urbanization carbon emission index", that is, the ratio of per capita carbon emission and urbanization rate, to show the relationship between the degree of urbanization and carbon emission. Through benchmarking analysis, we can more clearly understand the overall trend of low-carbon city construction in different countries, recognize the gap between China and other countries, and better guide the development of lowcarbon cities in China in the future.

\subsection{Comparison of comprehensive status}

\subsubsection{Total and average carbon emissions}

It can be seen from the comparison between China and other countries in 2017 that the total amount of China's $\mathrm{CO} 2$ emission is several times that of other countries except the United States, which is a high carbon emission country (Figure 1). However, in terms of per capita carbon emissions, due to the large population base, China's per capita carbon emissions are relatively low, only higher than the UK, Sweden, Mexico, Indonesia and India in the 12 comparison countries (Figure 2). Compared with the carbon emission per unit GDP, China's indicators are significantly higher, second only to South Africa, and higher than all countries with stable urbanization rate. The countries with higher carbon emission per unit GDP are South Africa, China, India and Indonesia, all of which are in the initial stage or accelerated stage of urbanization. This shows that these countries have strong dependence on energy in the process of economic growth and low utilization of energy, which is not conducive to the construction of low-carbon cities (Figure 3).

At the same time, from the comparison of per capita carbon emissions, it can be found that some developed countries, such as the United States, Australia, South Korea and so on, are in the high stage. It also reflects that this type of country has room for emission reduction.

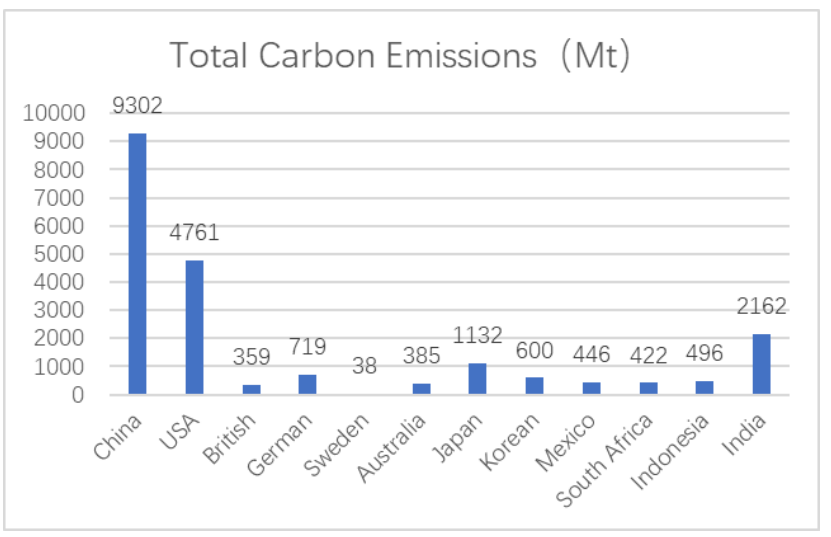

Fig. 1. Comparison of total $\mathrm{CO}_{2}$ emission between China and other countries

Data source: Based on 2017 data of International Energy

Agency (IEA. Http://www.iea.org/).

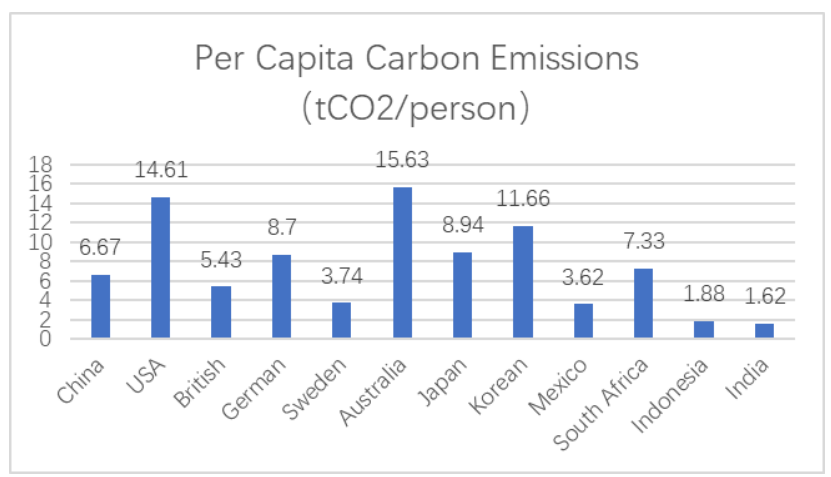

Fig. 2. Comparison of Per Capita $\mathrm{CO}_{2}$ emission between China and other countries

Data source: Based on 2017 data of International Energy

Agency (IEA. Http://www.iea.org/).

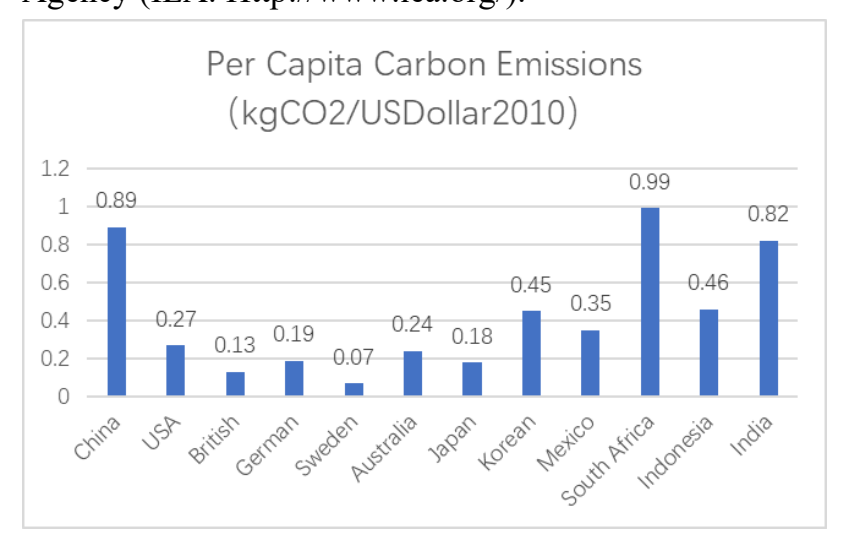


Fig. 3. Comparison of carbon emission Per Unit GDP between China and other countries

Data source: Based on 2017 data of International Energy

Agency (IEA. Http://www.iea.org/).

\subsubsection{Energy structure}

As carbon emissions are mainly generated through energy consumption, in the energy type, coal, oil and natural gas are all fossil energy, and certain carbon emissions will be generated in the process of consumption. Among them, coal combustion produces the highest carbon emissions, followed by oil and natural gas.

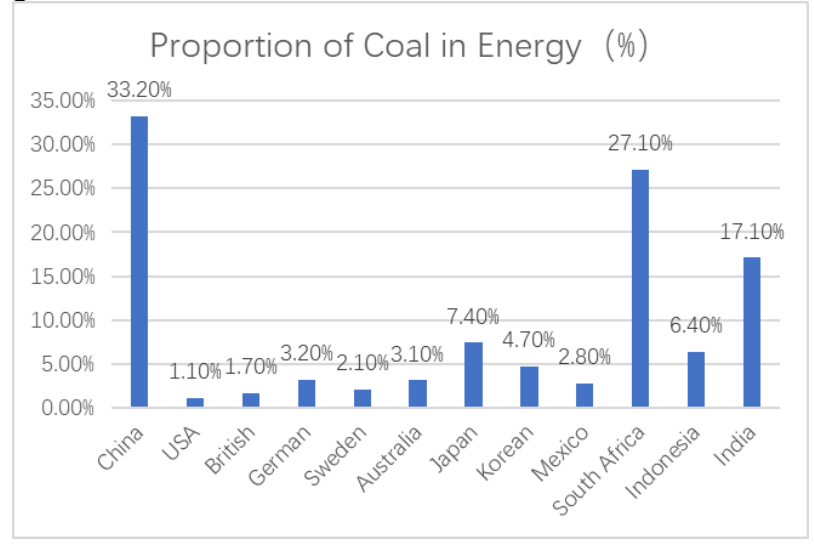

Fig. 4. Coal as a share of energy in China and other countries Data source: Based on 2017 data of International Energy Agency (IEA. Http://www.iea.org/).

In the comparison of energy structure, it can be seen that China's coal accounts for the highest proportion of all energy sources, reaching $33.2 \%$. All countries with stable urbanization rates are below $8 \%$, while coal accounts for a relatively high proportion of energy in South Africa and India (Figure 4). This shows that the energy structure of countries with stable urbanization rate is relatively reasonable. While reducing the total consumption of fossil energy in the future, China should continue to reduce the proportion of coal, use non fossil energy and renewable energy as much as possible, so as to gradually reduce the proportion of fossil energy in energy, and then reduce the total carbon emissions.

\subsubsection{Trend of Carbon Emission in Recent Years}

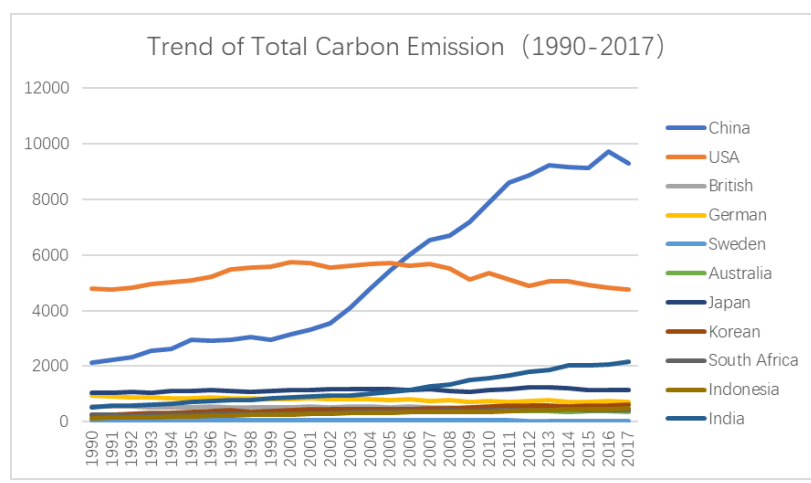

Fig. 5. Total carbon emission change map of China and other countries (1990-2017)

Data source: Based on 2017 data of International Energy

Agency (IEA. Http://www.iea.org/).

Comparing the total carbon emissions of China and other countries over the years from 1990 to 2017, it is found that China's total carbon emissions show a rapid increase trend after 2000, and only slowed down after 2013. Among other countries, only India has shown a rapid increase in recent years. From this point of view, China has great pressure on emission reduction (Figure 5). At the same time, it can be seen that China's carbon emission trend is generally stable after 2013, which shows that China's low-carbon policy implemented in this period has achieved remarkable results. China's low-carbon development has entered a new stage, and the new development concept and development mode are conducive to China's $\mathrm{CO} 2$ emission peaking as soon as possible, which is expected to achieve sustained economic growth and the fundamental improvement that the total carbon emission will not increase or even decrease.

\subsubsection{Comparison of Urbanization Carbon Emission Index}

In this paper, the ratio of per capita carbon emission and urbanization rate is used to express the "urbanization carbon emission index" to reflect the relationship between the degree of urbanization and carbon emission. The ratio increases, indicating that the carbon emission is also increasing in the process of urbanization. The smaller the ratio, indicating that the smaller the carbon emission is in the process of urbanization, showing the trend of low carbon development.

The calculation method of urbanization carbon emission index is as follows:

$$
\left.\mathrm{CO}_{2} \text { Emission Per Person( } \mathrm{TCO}_{2} / \mathrm{P}\right)
$$

\section{$\mathrm{F}(\mathrm{x})=$ \\ Urbanization Rate(\%)

$$
\mathrm{F}(\mathrm{x})=\text { Urbanization Carbon Emission Index }
$$

Table 1. Changes of urbanization carbon emission index of China and other countries (1990-2017)

\begin{tabular}{|l|l|l|l|l|l|l|}
\hline $\begin{array}{l}\text { year/ } \\
\text { country }\end{array}$ & China & USA & British & German & Sweden & Australia \\
\hline 1990 & 7.05 & 25.5 & 12.29 & 16.2 & 7.32 & 17.6 \\
\hline 1995 & 7.84 & 24.62 & 11.45 & 14.26 & 7.7 & 18.45 \\
\hline 2000 & 6.88 & 25.65 & 11.23 & 13.29 & 6.98 & 20.62 \\
\hline 2005 & 9.79 & 24.12 & 11.01 & 12.72 & 6.45 & 21.12 \\
\hline 2010 & 11.91 & 21.39 & 9.34 & 12.27 & 5.77 & 20.43 \\
\hline 2015 & 11.95 & 18.78 & 7.32 & 11.57 & 4.38 & 18.32 \\
\hline 2017 & 11.27 & 18.14 & 6.38 & 10.66 & 4.07 & 17.81 \\
\hline $\begin{array}{c}\text { year/ } \\
\text { country }\end{array}$ & Japan & Korean & Mexico & $\begin{array}{l}\text { South } \\
\text { Africa }\end{array}$ & Indonesia & India \\
\hline
\end{tabular}




\begin{tabular}{|l|l|l|l|l|l|l|}
\hline 1990 & 10.9 & 7.33 & 4.13 & 12.48 & 2.42 & 2.39 \\
\hline 1995 & 11.42 & 10.13 & 4.2 & 11.32 & 2.88 & 2.74 \\
\hline 2000 & 11.39 & 11.55 & 4.78 & 10.77 & 2.88 & 3.03 \\
\hline 2005 & 10.62 & 11.69 & 5.05 & 12.83 & 3.05 & 3.22 \\
\hline 2010 & 9.69 & 13.58 & 4.96 & 13.05 & 2.95 & 4.17 \\
\hline 2015 & 9.95 & 13.98 & 4.62 & 11.67 & 3.34 & 4.73 \\
\hline 2017 & 9.49 & 14.82 & 4.41 & 11.19 & 3.4 & 4.74 \\
\hline
\end{tabular}

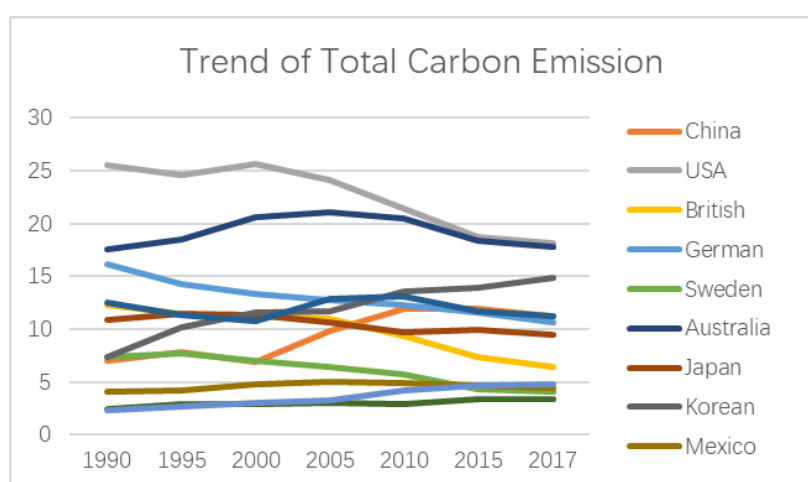

Fig. 6. Change of urbanization carbon emission index in China and other countries (1990-2017)

Data source: International Energy Agency, IEA. http://www.iea.org/. United Nations, Department of Economic and Social Affairs, Population Division

From the change trend of "urbanization carbon emission index", China's index shows an upward trend, reaching a peak in 2015, and then falling back, which shows that China's carbon emission shows an increasing trend in the process of urbanization, and the country needs efforts in the overall emission reduction. Most of the stable urbanization countries, such as the United States, the United Kingdom, Germany, Sweden, Japan and so on, show a downward trend, reflecting the actual contribution of these countries in the field of reducing carbon emissions in recent years. In the stable urbanization countries, only the index of South Korea shows an upward trend. At the same time, in the countries of accelerating urbanization and the countries of primary stage urbanization, the index of Indonesia and India also shows an upward trend, indicating that these two countries have not done enough in the field of overall carbon reduction (Table 1, Figure 6).

In the future, with the continuous improvement of China's urbanization level, how to decouple carbon emission from urbanization and realize the annual decline of "urbanization carbon emission index" is a problem worthy of consideration.

\section{Conclusion and discussion}

After benchmarking the carbon emission indicators of China and countries with different urbanization rates, it can be seen that no matter which stage of urbanization is in, China's carbon emission and energy utilization show three major characteristics, namely, large total carbon emission, large carbon emission per unit GDP and high proportion of coal in energy (Table 2).
Table 2. Comparison of the significantly high index between China and other countries

\begin{tabular}{|c|c|c|c|c|c|c|c|}
\hline \multirow{2}{*}{ Factor } & \multirow{2}{*}{$\begin{array}{l}\text { Chin } \\
\text { a }\end{array}$} & \multicolumn{2}{|c|}{$\begin{array}{l}\text { Stable } \\
\text { Urbanization } \\
\text { Stage }\end{array}$} & \multicolumn{2}{|c|}{$\begin{array}{l}\text { Accelerated } \\
\text { Urbanization } \\
\text { Stage }\end{array}$} & \multicolumn{2}{|c|}{$\begin{array}{l}\text { Primary } \\
\text { Urbanization } \\
\text { Stage }\end{array}$} \\
\hline & & $\begin{array}{l}\text { Averag } \\
\mathrm{e}\end{array}$ & $\begin{array}{l}\text { Chin } \\
\text { a/Av } \\
\text { erage }\end{array}$ & $\begin{array}{l}\text { Aver } \\
\text { age }\end{array}$ & $\begin{array}{l}\text { China/ } \\
\text { Averag } \\
\mathrm{e}\end{array}$ & $\begin{array}{l}\text { Aver } \\
\text { age }\end{array}$ & $\begin{array}{l}\text { Chin } \\
\text { a/Av } \\
\text { erage }\end{array}$ \\
\hline $\begin{array}{l}\text { Total } \\
\text { Carbon } \\
\text { Emissi } \\
\text { ons } \\
\text { (Mt } \\
\text { ) }\end{array}$ & 9302 & 1040.5 & 8.9 & 459 & 20.27 & 2162 & 4.3 \\
\hline $\begin{array}{l}\text { Per } \\
\text { Capita } \\
\text { Carbon } \\
\text { Emissi } \\
\text { ons } \\
\text { (kgC } \\
\text { O2/US } \\
\text { Dollar2 } \\
010)\end{array}$ & 0.89 & 0.3 & 3 & 0.73 & 1.22 & 0.82 & 1.09 \\
\hline $\begin{array}{l}\text { Proport } \\
\text { ion of } \\
\text { Coal in } \\
\text { Energy } \\
(\%)\end{array}$ & 33.2 & 3.49 & 9.51 & $\begin{array}{l}16.7 \\
5\end{array}$ & 1.98 & 17.1 & 1.94 \\
\hline
\end{tabular}

Data source: Based on 2017 data of International Energy

Agency (IEA. Http://www.iea.org/)

These three characteristics show that China's carbon emission reduction pressure is still very huge. Among them, large-scale industry, large proportion of coal in energy, low energy utilization rate and less clean energy utilization are the main reasons. At the same time, the dependence of China's economic development on energy consumption is also the main reason for China's large carbon emissions per unit of GDP.

From the perspective of the overall trend change from 1990 to 2017, China's total carbon dioxide emissions show an increasing trend year by year, and in the statistics of "urbanization carbon emission index", China also shows a rapid upward trend. It shows that the development of urbanization in China has a certain role in promoting the increase of carbon emissions, which is obviously different from that of stable urbanization countries. In the stable urbanization countries, the "urbanization carbon emission index" of most countries shows a trend of decreasing year by year, which shows that the carbon emission intensity has not been strengthened with the improvement of urbanization, and has realized the decoupling of carbon emission and urbanization.

The process of urbanization involves many aspects such as economy, society and environment of each country. At present, China is in the rapid stage of urbanization. If we still follow the past development mode, and promote the intensity of carbon emission while increasing urbanization, it will violate China's responsibility of emission reduction in the world.

For China, the extensive development path of high growth, high consumption and high emission has increased the consumption of energy and made the living 
environment worsen rapidly. As a developing country, the contradiction between economic development, resource consumption and environmental pollution is an urgent problem to be solved in China. While learning from the experience of other countries, we should also start from China's actual interests, fully consider the national conditions, and put forward low-carbon development policies and carbon reduction goals. China must work with the international community to actively respond to climate change and assume corresponding responsibilities and obligations for emission reduction. This has brought great opportunities for the development of China's low-carbon cities, as well as great challenges for China to better demonstrate its image as a responsible country to the international community.

\section{Acknowledgements}

This research is supported by China National Social Science Fund, No. 19BJY063 , The IV Peak Plateau Discipline of Shanghai Design, Key Courses in Shanghai.

\section{References}

1. People website. "Global warming $1.5{ }^{\circ} \mathrm{C}$ special report".2018-10-12.

http://env.people.com.cn/n1/2018/1012/c101030336878.html.

2. United Nations Press. Katowice climate change conference: countries reach further agreement on specific plans for the implementation of the Paris Agreement.2018-12-15. https://news.un.org/zh/story/2018/12/1024941

3. Liu Changshong. What are the highlights of the 2019 UN climate summit? [N]. China Environmental News,2019-09-27(003).

4. China carbon trading network. Britain released its second climate change adaptation plan. 2018-08-24. http://www.tanjiaoyi.com/article-24668-1.html.

5. People website. Canada will "push" the carbon emission pricing system nationwide.2018-10-24. http://yn.people.com.cn/n2/2018/1024/c37844132197466.html.

6. Xin Hua Press. ive Nordic countries sign climate statement to speed up "carbon neutrality".2019-01-28. http://www.xinhuanet.com/energy/201901/28/c_1124050703.htm.

7. China Power News Network. German energy report: Fair transition from coal to renewable energy.201911-22. http://www.cpnn.com.cn/zdyw/201911/t20191122_1 176220.html.

8. China Report. The millennium plan behind the "four ones".2019-03-07.

http://www.china.com.cn/lianghui/news/201903/07/content_74542285.shtml.
9. Government of P.R.China. Three year action plan to win the blue sky defense war.2018-07-03. http://www.gov.cn/zhengce/content/201807/03/content_5303158.htm.

10. China News. Li Keqiang: to promote the development of regional integration in the Yangtze River Delta as a national strategy 。2019-03-05. http://www.chinanews.com/gn/2019/0305/8771708.shtml.

11. Comprehensively promote the planning and construction of xiong'an new area to develop in depth [N]. Be Bei Daily,2019-01-03(003).

12. Northam R M. Urban Geography. New York: J. Wiley Sons, 1975. 